\title{
A Fragile Life: Vulnerable Species in the Torrid Zone
}

\author{
Dr Robyn Glade-Wright
}

James Cook University

\begin{abstract}
This paper examines the potential for visual art to communicate concerns about vulnerable species in the Torrid Zone. The processes of selecting materials and symbolic forms to articulate these concerns will be described. Aesthetics considerations are discussed in relation to the capacity of art to generate reflection.
\end{abstract}

$\mathrm{E}$ xtinction is a worrying reality. The termination of a species eliminates possible relationships between living entities. My concern regarding extinction was heightened when I realised that the current mass extinction event is a result of human agency and that extinction rates are estimated to be one hundred to one thousand times higher than what is considered to be natural. This uncomfortable and inconvenient truth has inspired my artwork. In this work I have attempted to communicate my concerns about species loss with the aim of generating reflection. If people are charged with minding nature, our report card on species loss is something needing attention. The aim of my art is to raise awareness so that endangered and vulnerable spices may be saved. In the following I will describe the symbolic means I employed to construct the artwork and theories that inform the aesthetic aspects of the work.

Somewhat surprisingly, my initial concern about species loss was raised by a natural hedge. This occurred after I had spent a week bush walking in the Tasmanian natural environment. While this environment had been home to indigenous peoples for around 40 thousand years, it was devoid of debris from Western society. During the drive home, I was startled by the sight of a long hedge. This well manicured hedge consisted of a single plant species, with each plant arranged in a perfectly aligned single file. The visual shock was unexpected. My visual system must have adapted to the diversity of the plants, hills, rocks and sky in the bush that I had lived amongst for the past week.

The elements of the natural environment such as plants, rocks, pools and streams appear to have deep connections and their relationships seem to have been developed over a longer period of time than I can imagine. By contrast, the plants in the manicured hedge sat uncomfortably in a single file. Over the next week, my visual system adapted to the sights of the city, however, I felt a sense of disquiet. I pondered what we have lost in the built environment and what we have created in our haste for economic gain. In contrast to the seeming harmonious relationships between the plants, rocks, sky and waterways in the natural environment, the city appeared to be barren and inhospitable. At this time the binary of emptiness in the city and connectedness in the bush, lead me to consider what else we may have lost in our civilized, tripled fronted, online, hectic lives. My thoughts drifted to the numerous 
plants and animals that we had lost due to extinction. It occurred to me that the extinction of an increasing number of plants and animals could one day render the natural environment as soulless as the city and the hedge.

From this time, I started researching extinct plants and I produced a body of digital images with the intention of creating live art as shown in Figure 1. My aim was to project gently moving images onto interior walls to emulate the movement of the sun and clouds and the changing light conditions like that I experienced in the natural environment. Technological limitations and prohibitive cost culled this plan, so I searched for alternative techniques to convey my concerns. I commenced a body of hand stitched pieces on organza which is designed to cast shadows on the gallery wall. There is a disquieting aspect to the shadows that are both absent and quietly beautiful, much like the extinct plants I was seeking to represent.

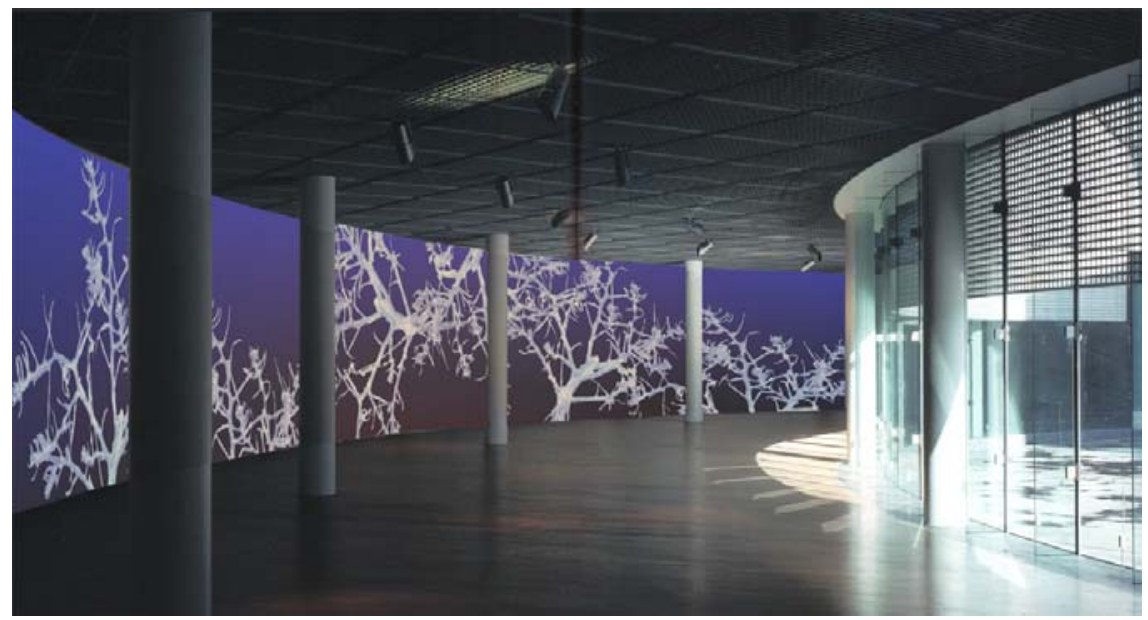

Figure 1. Myriophyllum glomeratum, Virtual wall installation 2003. Digital image, $40 \mathrm{~cm} \times 21 \mathrm{~cm}$.

To increase the emotive power of the work, I investigated psychological triggers that were associated with human death and sought ways to link these with extinct plants. Wreath and funeral urns are associated with the commemoration of people and the conflation of these forms, with plant extinction provides the potential to increase the emotive power of the work. I fabricated funeral urns (Figure 2) and embroidered wreaths to commemorate extinct plants (Figure 3). A further instance of this type of merging together was the memorial board. Such honour boards are often used in town halls to commemorate great loss of fallen soldiers. In Tasmania there were eighteen extinct plants when I commenced this work in 2002. The number grew each year and reached twenty-six when I completed the work four years later. To capture the currency of extinction, I created a memorial board to record the loss of plants in our time. My recent work has focused on the vulnerability of endangered species from the Torrid Zone. My artworks depicting vulnerable animal eggs, attempts to capture the fragility of existence of these species as they teeter on the edge of existence. 


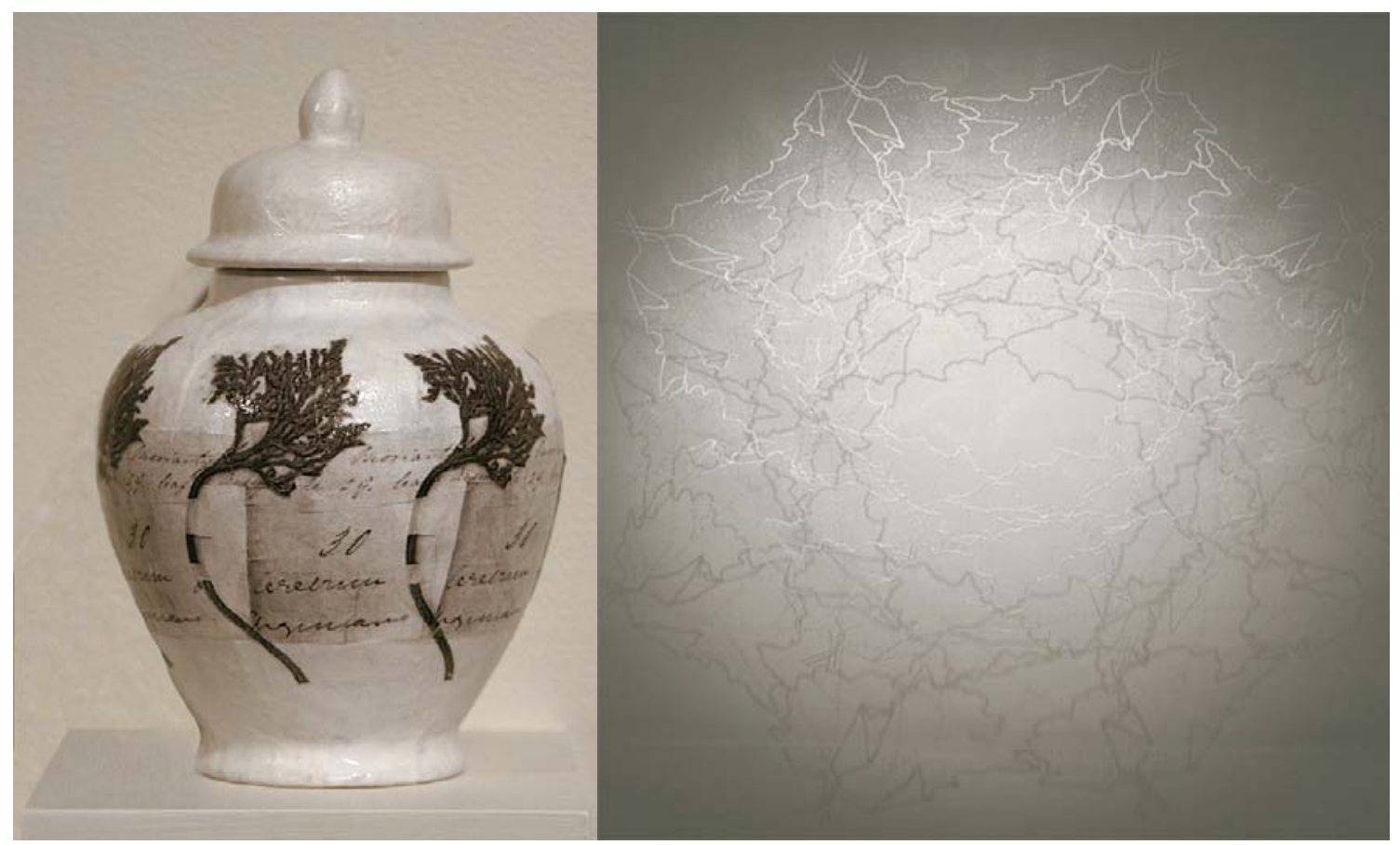

Figure 2. Funeral urn for

Botrychium austral 2006.

Ceramic, digital image, glaze.

$20 \mathrm{~cm} \times 10 \mathrm{~cm} \times 10 \mathrm{~cm}$
Figure 3. Wreath for Chenopodium erosum 2005. Polyester organza, cotton thread, hand stitch. $110 \mathrm{~cm} \times 110 \mathrm{~cm}$.

My artwork is often described as being beautiful and this has been somewhat of a moot point, as for many years during the rein of modernism, beauty was out of favour. From the $18^{\text {th }}$ century when the famed philosophers Burke and Kant sub-divided the aesthetic realm into those of beauty and the sublime, beauty suffered a long fall from grace. As I was working with the "blight of beauty" I investigated its secret power.

Following a study of the two hundred and fifty thousand years of philosophical musing about beauty, I came to understand that according to some authors such as Australia's own John Armstrong (2004) and the American philosopher Elaine Scarry, (1999) that the power of beauty could be attributed to relationships and stewardship.

Relationships are central to the experience of beauty according to Armstrong and these relationships could be triggered by emotion, desire or sentiment (2004). To briefly illustrate this point, the appearance of your first child, or your first grandchild is highly likely to lead you to conclusion that the newborn child is beautiful. This is what I thought of my first child, however, years later I recognised she was an ugly baby. The mother child relationship made me 'see' a beautiful baby for her whole infancy.

Stewardship was an aspect of beauty described by Elaine Scarry. Scarry writes that when we see a beautiful object such as an Ancient Greek vase, we are inclined to protect it and to emulate or to copy it (1999). We may want to make a copy of the vase to reproduce its beauty. This idea of stewardship apparently explains why people are concerned to hear about the death of large kelp forest in the southern ocean even when in all likelihood they would never see the kelp. People seem to intuitively know that beauty is good for others, even if they will not enjoy its rewards. 
This idea of stewardship, coupled with that of relationship were central to the use of beauty in my work. If Scarry and Armstrong were correct, I could create beautiful renditions of extinct plants, even if in fact the plants were ugly, in the hope that the work would illicit concern for the extinct plants. This could generate sentiments of longing and regret about their loss and potentially, it could engender a more considered approach to the way we live. In many respects my use of beauty in this work is subversive. The beauty promised by the works is lost, as the plants are extinct. The potential for a relationship with these living entities is extinguished forever.

I question my art in relation to whom I am serving. In the end, is my concern for the vulnerable and endangered plants and animals really the concern for the plant, or the threat their loss poses to human life? We know that the biosphere is less likely to be able to support life as biodiversity reduces. According to Hepburn, the real subject of art is 'always the human subject' (1995, p. 422). At some levels, my artwork is similarly about the human subject and this perturbs me.

\section{Works Cited}

Armstrong, J 2004,The Secret Power of Beauty, Allen Lane, London.

Scarry, E 1999, On Beauty and Being Just, Princeton University Press, Princeton.

Hepburn, R 1995, 'Theories of Art', in D Cooper (ed.), A Companion to Aesthetics, Blackwell, Oxford. 